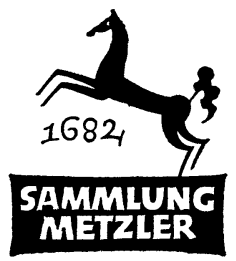

REALIENBÜCHER FÜR GERMANISTEN ABT. D:

LITERATURGESCHICHTE 
JOACHIM MÜLLER

\section{Franz Grillparzer}

MCMLXIII

J.B. METZLERSCHE VERLAGSBUCHHANDLUNG

STUTTGART 
ISBN 978-3-476-99716-6 ISBN 978-3-476-99715-9 (eBook) DOI 10.1007/978-3-476-99715-9

\section{$M_{3 I}$}

(C) Springer-Verlag GmbH Deutschland 1963

Ursprünglich erschienen bei J. B. Metzlersche Verlagsbuchhandlung und Carl Ernst Poeschel Verlag GmbH in Stuttgart 1963 


\section{INHALT}

I. Handschriften, Ausgaben, Bibliographien, ForSCHUNGSBERICHTE, GESAMTWÜRDIGUNGEN . . . . . . . I I

II. HISTORISCHE UND LITERARHISTORISCHE VORAUSSETZUNGEN 9

III. LEBEN UND WERK . . . . . . . . . . . . . . . . . . I6

I. "Blanka von Kastilien", lyrische Entwürfe, dramatische Entwürfe

Herkunft, Kindheit und Jugend (1791-1817) . . . . . 16

2. "Die Ahnfrau", "Sappho"

Die ersten Erfolge (1817-1818)

3. "Das Goldene Vließ", Lyrik, Epigramme

Italienreise, Verwicklung in Wiener Intrigen (1818 bis I82I)

4. "König Ottokars Glück und Ende«

Beziehungen zu Frauen nach der Rückkehr und erste Bekanntschaft mit Kathi Fröhlich (1821-1826/27) . . . 38

5. Affaire Ludlamshöhle und Deutschlandsreise (1826) . • 44

6. "Ein treuer Diener seines Herrn" (1 826-1 828)

7. "Des Meeres und der Liebe Wellen «, »Der Traum ein Leben" $(1828-1836)$. . . . . . . . . . . . . .

8. "Weh dem der lügt"

Reisen nach Paris und London (1836-1838)

9. "Das Kloster bei Sendomir", "Der arme Spielmann", "Esther", "Libussa", "Die Jüdin von Toledo", "Ein Bruderzwist in Habsburg "

Rückzug aus der Öffentlichkeit. Höhepunkt der dichterischen Produktion (1838-1848) . . . . . . . .

ro. Politische Konflikte. Späte Ehrungen. Alter und Ausklang (1 848-I 872)

IV. Bildungstradition und KunstanschauUng Aufsätze . . . . . . . . . . . . . . . . . . . .

V. Versuch einer Gesamtwürdigung von Grillparzers DICHTERISCHEM WERK . . . . . . . . . . . . .

VI. Geschichte, Stand und Aufgaben der GrillparzerFORSCHUNG. WIRKUNGSGESCHICHTE . . . . . . . . . 94 Register . . . . . . . . . . . . . . I07 


\section{AbKüRZUngen}

$\mathrm{ADB}=$ Allgemeine Deutsche Biographie

AfdA = Anzeiger für deutsches Altertum

AfStSpr. = Archiv für das Studium der neueren Sprachen

Comp. Lit. $=$ Comparative Literature

DLZ = Deutsche Literatur-Zeitung

DVjs. = Deutsche Vierteljahrsschrift für Literaturwissenschaft und Geistesgeschichte

$\mathrm{DuV}=$ Dichtung und Volkstum

Euph. $\quad=$ Euphorion

GRM = Germanisch-Romanische Monatsschrift

JbFDH = Jahrbuch des Freien Deutschen Hochstifts

JbGrGes. = Jahrbuch der Grillparzer-Gesellschaft

JEGPh. = Journal of English and Germanic Philology

Monatshefte $=$ Monatshefte für deutschen Unterricht (Wisconsin/ USA)

NF $\quad=$ Neue Folge

PMLA = Publications Modern Language Association

SB $\quad=$ Selbstbiographie

Tgb. = Tagebuch

WA (auch: Hist.-

krit. Ausg.) $=$ Wiener Ausgabe

WW $\quad=$ Wirkendes Wort

ZfdA = Zeitschrift für deutsches Altertum

ZfDk. = Zeitschrift für Deutschkunde

ZfdPh. $\quad=$ Zeitschrift für deutsche Philologie 